\title{
Los partos domiciliarios planificados se asocian a una mayor tasa de mortalidad neonatal
}

\section{Planed home births are associated with increased neonatal mortality}

\section{Objetivos}

Realizar una revisión sistemática de la literatura médica sobre resultados maternos y neonatales de los partos domiciliarios planificados versus los partos hospitalarios, ambos atendidos por personal certificado.

\section{Fuente de datos}

Los autores incluyeron publicaciones en inglés, revisadas por pares, de países occidentales desarrollados, obtenidas de búsquedas en MEDLINE y EMBASE.

\section{Selección de datos}

Se seleccionaron los artículos que reportaran resultados maternos y neonatales discriminados por lugar del parto y aquellos en que los partos hubieran sido asistidos por personal certificado. De las 237 citas identificadas en primera instancia, sólo 12 artículos fueron incluidos en el metaanálisis. Los países involucrados en los estudios fueron Estados Unidos, Canadá, Reino Unido, Australia y Europa occidental.

\section{Extracción de datos}

El período de estudio de estos doce artículos, en conjunto, fue de 1976 a 2006. En total se analizaron 342.056 partos domiciliarios

Tabla 1:

\begin{tabular}{|c|c|c|c|}
\hline Resultado & Parto domiciliário planificado n/N (\%) & Parto hospitalario $\mathrm{n} / \mathrm{N}(\%)$ & OR (IC 95\%) \\
\hline \multicolumn{4}{|l|}{ Mortalidad perinatal } \\
\hline Todos & $229 / 331.666(0,07)$ & $140 / 175.443(0,08)$ & $0,95(0,77$ a 1,18$)$ \\
\hline Recién nacidos normales & $225 / 330.324(0,07)$ & $134 / 173.266(0,08)$ & $0,95(0,76$ a 1,18$)$ \\
\hline \multicolumn{4}{|l|}{ Mortalidad neonatal } \\
\hline Todos & $32 / 16.500(0,20)$ & $32 / 33.302(0,09)$ & $1,98(1,19$ a 3,28$)$ \\
\hline Recién nacidos normales & $23 / 15.633(0,15)$ & $14 / 31.999(0,04)$ & $2,87(1,32$ a 6,25$)$ \\
\hline
\end{tabular}

Wax JR y col. Am J Obstet Gynecol 2010;203(3):243.e1-8. planificados y 207.551 partos hospitalarios.

\section{Resultados principales}

Al analizar los resultados maternos, los autores observaron que los partos domiciliarios se asociaron significativamente a una menor intervención médica, medida a través de la analgesia epidural, el monitoreo fetal, la episiotomía, el parto operatorio y la cesárea. Del mismo modo, los partos domiciliarios se asociaron significativamente a una menor morbilidad, medida a través de desgarros de tercer grado o más, infección, hemorragia postparto, retención placentaria y laceración perineal y vaginal.

Respecto de los resultados neonatales, los autores observaron que el parto domiciliario se asoció con menor tasa de prematuridad y de bajo peso al nacer, y con mayor tasa de embarazos prolongados y de recién nacidos que requirieron ventilación pulmonar. La mortalidad perinatal fue similar para ambos grupos, sin embargo, se hallo una asociación estadísticamente significativa en la mortalidad neonatal (hasta los 28 días), la cual fue analizada en siete de los doce estudios incluidos, y resulto dos veces mayor entre los nacidos en partos domiciliaros planificados versus los nacidos en partos hospitalarios, y casi tres veces mayor al analizar sólo los recién nacidos $(\mathrm{RN})$ normales.

$\mathrm{n} / \mathrm{N}$ : numero de casos/población expuesta. OR: odds ratio

\section{Conclusiones}

Este metaanálisis encontró una tasa de mortalidad perinatal similar entre ambos grupos, sin embargo, fue un hallazgo inesperado el aumento en la tasa de mortalidad neonatal observado en el grupo de parto domiciliario. Esto es particularmente robusto, si se considera la homogeneidad en las observaciones de los distintos estudios. Y es especialmente llamativo el hecho de que las mujeres que planearon sus partos en el domicilio presentaron similar o menor riesgo obstétrico que las que planearon el parto en el hospital.

Palabras claves: partos domiciliarios, partos hospitalarios, mortalidad perinatal, mortalidad neonatal. Key words: home birth, hospital birth, perinatal mortality, neonatal mortality. Fuente de financiamiento: No se refiere.

\section{Comentario}

Si bien los resultados de este metaanálisis, proveniente de datos de países con culturas diferentes y con realidades sanitarias distintas a las nuestras, no son del todo extrapolables a nuestra realidad, no deja de ser llamativa la asociación encontrada entre el lugar del parto y la tasa de mortalidad neonatal, en ausencia de asociación con la mortalidad perinatal.

Si bien los autores barajan la posibilidad de que la asociación entre el parto domiciliario y el aumento de la mortalidad neonatal se deba a la menor intervención obstétrica recibida por este grupo, considero que debería analizarse cuál es la percepción de estas mujeres o de estas parejas para con el sistema de salud. Entiendo que una hipótesis a estudiar es la posible aversión que estos seguidores del parto domiciliario tienen por la intervención médica, lo que los puede llevar a que frente a situaciones de riesgo de sus hijos, consulten más tardíamente, hecho que claramente contribuye a aumentar la mortalidad perinatal.

\section{Conclusiones del comentador}

En estos tiempos en que el parto domiciliario gana cada vez más adeptos, este estudio pone de manifiesto la necesidad de analizar su impacto en nuestro medio, a fin de poder evaluar si se repiten o no los mismos resultados, y para analizar, en caso de encontrarse asociación entre lugar del parto y resultados perinatales o neonatales los factores implicados.

Lic. Ana María Bonotti [ Programa Materno Infantil del Ministerio de Salud de la Provincia de Buenos Aires. ambonotti@gmail.com ] 